\title{
DRAWING INSPIRATION FROM THE SPINE, DESIGNING A PEDESTRIAN BRIDGE [SPINE-INSPIRED DESIGN OF A PEDESTRIAN BRIDGE]
}

\author{
Nikoo GOLKAR (D), Amirhossein SADEGHPOUR (D), Javad DIVANDARI (D) \\ School of Architecture and Art, University of Kashan, Isfahan, Iran \\ Received 10 September 2020; accepted 04 June 2021
}

\begin{abstract}
Natural structures are known to be the source of inspiration for numerous architectural and structural rules in the fields of aesthetics, function, and structure; therefore, the application of the principals governing them could be used for appropriate and optimal design. The present paper was conducted to model the natural structure of load transfer in order to design the structure of a pedestrian bridge with a span of 100 meters. This bridge is located in a mountain park in the tourist area of Kashan, $230 \mathrm{~km}$ south of Tehran. For this purpose, by examining the patterns in the nature, which provides a relevant answer to the problem, the spine of animals was identified as the bearing skeleton of the body, the best option for patterning. Inspired by it, a stable structure was designed as a skeleton of a bridge without a middle pillar. Based on a form inspired by the spine of a four-legged animal, the bridge structure was designed. To control the stability of the bridge structure against the loads, the initial design idea was analysed employing the Karamba plugin in Grasshopper software to identify its weaknesses and the final design was obtained. The final design was analysed with SAP2000 structural finite element software to ensure the stability and control of permissible deformations. Additionally, attention to the modular structure of the spine was the source of inspiration for the design of prefabricated elements of the bridge parts, which in addition to reducing the cost of execution, increases the speed of construction of the project. The final design of the pedestrian bridge, which acts similar to a suspension bridge in terms of load transfer and was inspired by the structure of a four-legged vertebrate, is a combination of truss and tensegrity structure and in addition to visual aesthetic, has optimal structural performance.
\end{abstract}

Keywords: biomimetic, pedestrian bridge, bionics, structural design, bridge design, bio-inspired design.

\section{Introduction}

The structural system is an essential component of any entity with physical dimensions. In particular, the primary role of the system is to help the entity withstand physical loads, ensure its stability, and correct its function. However, overall, this system could also serve other purposes, for instance, aesthetic, organizational, and even cultural contributions. The term "structural design" refers to the art and know-how behind the creation of a structural system in the natural or the built world. "Structural design in nature" hints at the methods via which the nature is created (Mosseri, 2004).

Biomimicry, also known as bionics and biomimetics, is the comprehension of biological systems and adopting these concepts in creating artificial systems using the available technology, mainly aiming to achieve sustainability (Qaruni Esfahani, 2015). The significance of biology is obvious now to the scientific community that the twenty-first century-unlike the twentieth that was widely considered as that of physics-is the century of biology (Aziz \& El Sherif, 2016). In construction and civil engineering, biomimicry has also been transformative (Sarikaya, 1994), being utilized in the design of sustainable and optimized structures (Al-Sehail, 2017) or the production of innovative materials and composites.

Generally, bionic design could be applied through two methods, namely "top-down" or "problem-based" methods and "bottom-up" or "approach-based" methods. In the top-down approach, designers look for solutions in the nature in order to solve the problems identified in human life. In the bottom-up approach, the specific developed solutions are used to tackle the problems (Ali El-Zeiny, 2012).

The present study employed a top-down approach that involved six steps, namely (1) stating the problem, (2) analyzing the problem, (3) finding a biological solution, (4) defining the biological solution, (5) extracting principles, and (6) applying the principles (Ali El-Zeiny, 2012).

${ }^{\star}$ Corresponding author. E-mail: sadeghpour@kashanu.ac.ir 

below:

This paper followed a similar process, as explained

1. Statement and analysis of the problem: the addressed problem herein was designing a pedestrian bridge made up of prefabricated components in a park in the Kuhpayeh district of Kashan, Iran. For this purpose, the site, goals, and design issues were evaluated.

2. Finding a biological solution and its definition: primarily, the function of the bridge was compared to the function of similar structures in the nature to see how it provides solutions to such matters. Among the proposed models, the spine is the most competent for the design goals. Comparing the human spine as a vertical structure to the animals', as a horizontal load-bearing structure in the face of incoming loads, was the next step to ensure the selection of an appropriate pattern. Based on the problem form, the analysis performed, and the biological solution for the design, the backbone of an animal was selected. The building blocks of the equine spine were then studied under the applied loads.

3. Principle extraction: this step involved going through the principles of load transmission over the quadruped spine, which was carried out by making scale models and conducting concept analysis using Karamba.

4. Applying the principles: the structural principles of the spine were then put into practice in the design of a pedestrian bridge and the ultimate product was analyzed using SAP2000 to ensure its stability.

\section{Literature review}

Over the recent decades, several bridges have been built, whose designs are inspired by biological structures of various scales. Hu et al. (2013) put forth five models for nature-inspired designs applicable for bridges, namely geometry, structure, mechanism, energy, and intelligence. Table 1 illustrates these models and their inspirational contexts.

The extent of the acceptability of the model from a bionics perspective depends on how further away we can move from the biological elements. In other words, the design will be even more valuable by going deeper and

Table 1. Aspects and objectives of inspiration towards the bioinspired bridge (Hu et al., 2013)

\begin{tabular}{|l|l|}
\hline Prototype in nature & \multicolumn{1}{c|}{ Bio-inspired goals } \\
\hline Geometry & Eye-catching and signature bridge \\
\hline Structure & $\begin{array}{l}\text { Material-adapted supporting and deck } \\
\text { system }\end{array}$ \\
\hline Mechanism & Deployable and moving bridge \\
\hline Energy & $\begin{array}{l}\text { Sustainable and multifunctional } \\
\text { bridge }\end{array}$ \\
\hline Intelligence & Self-control and smart bridge \\
\hline
\end{tabular}

beyond the apparent aspects of the biological elements and dominating the laws of the nature (Hu et al., 2013).

In his 2001 article, Vincent presented the "biomimetic map" (Figure 1), explaining the same concept. In this map, the first stage, total (formal) mimicry, is less credible, in contrast to the last one, inspiration, which mimics the nature in a more profound sense (Vincent, 2011).

Figure 2 represents an instance of formal mimicry in the design of the "dragon" bridge in Germany.

Figure 3 depicts the Campo Volantín footbridge, Spain, designed by Santiago Calatrava, a pioneer in bioinspired architecture. The bridge is inspired by the spinal

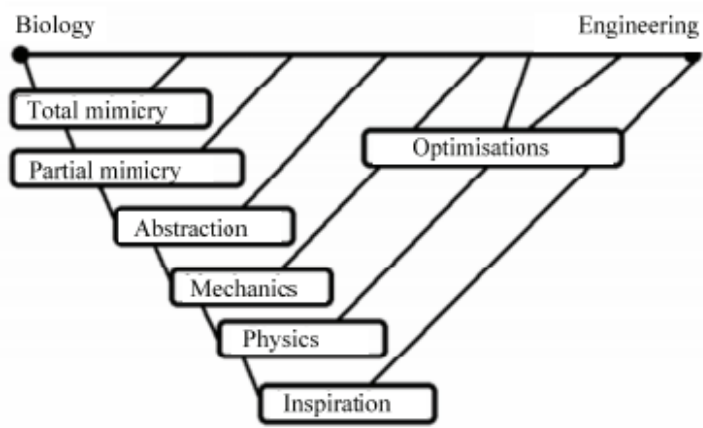

Figure 1. The biomimetic map (Vincent, 2011)

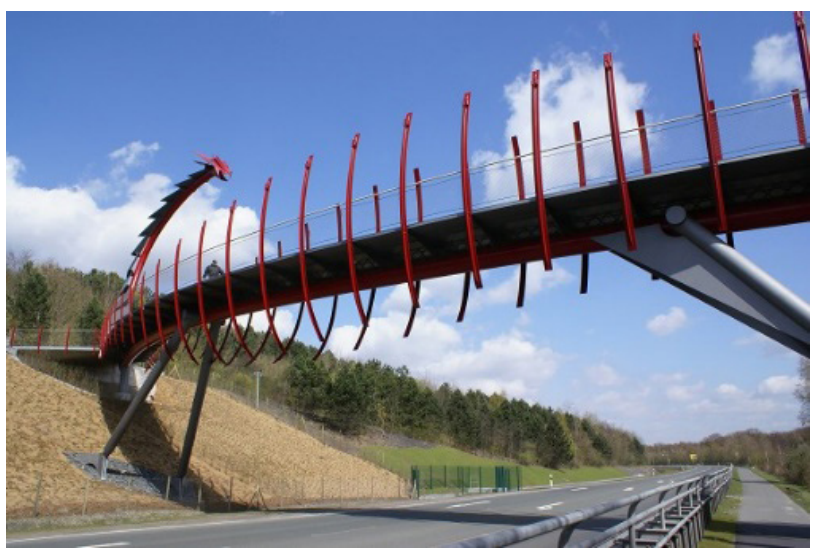

Figure 2. Dragon bridge, Germany, inspired by biological elements (total mimicry; Structurae, 2008)

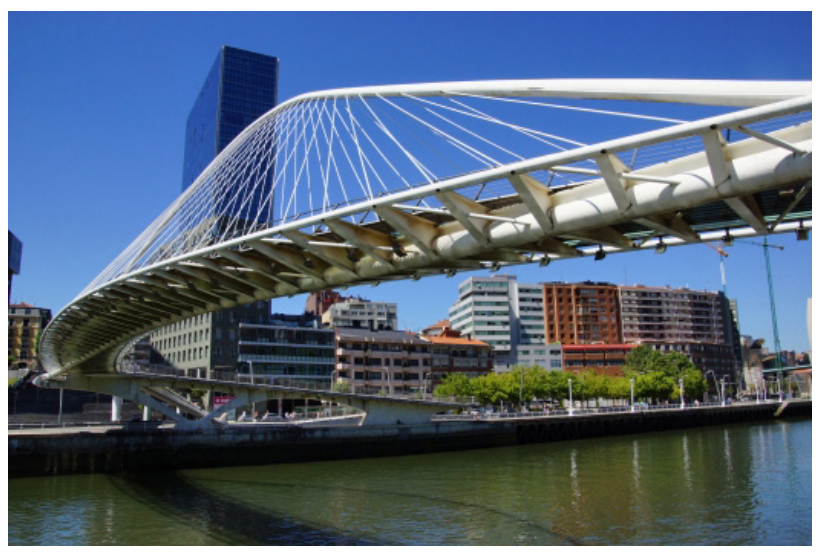

Figure 3. Campo Volantín footbridge, Spain; mechanical mimicry of the spine (Structurae, n.d.) 


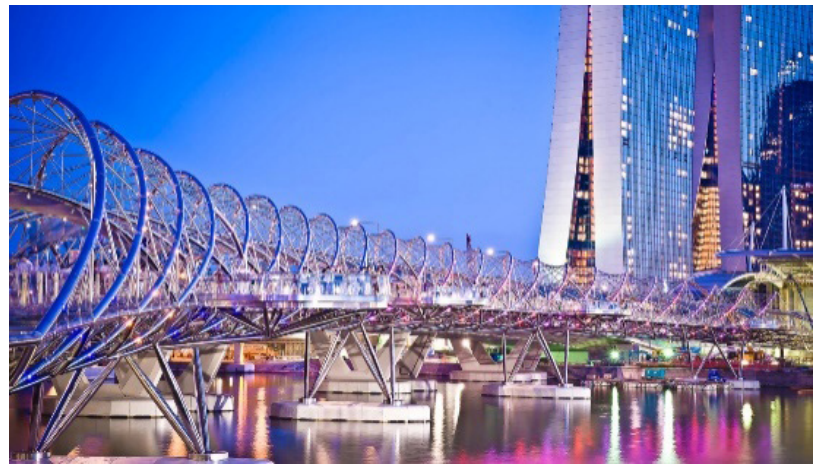

Figure 4. The Helix, Singapore; an abstraction of the DNA (Technolite, n.d.)

column for its structure and load transmission principles (mechanical mimicry). In the structure of this bridge, the deck and cable represent the spine and the muscles and tendons, respectively.

The supporting arc wrapping around the structure also resembles an animal's legs transferring loads to the ground (Sadeghpour et al., 2017).

The Helix (2009), Singapore, depicted in Figure 4, is another bridge inspired by the nature. The structure is a formal abstraction of the DNA molecule and boasts an intricate, pricey design (Hu et al., 2013).

Overall, it could be concluded that although architecture can be inspired by the nature at various scales, emulating the transfer and distribution of force in living structures, as an act of mechanical mimicry, provides the best solutions in bridge design, helping develop an optimal structure.

\section{Problem analysis}

\subsection{Project site}

Kashan is a city in the northern part of Isfahan province, Iran. Kashan's climate is a semi-arid climate. Figure 5 illustrates the location of Isfahan and Kashan in the map of climate division in Iran.

The project site is at one of Kashan's points of entry on Dorin Rd., in District 4. The tourist destination is home to Bam-e Shahr Park, an amusement park, the Chehel-Hesaran Park, and Amirkabir Stadium. The bridge will stretch over Dorin Rd., connecting Bam-e Shahr Park to the under-construction Phase 2 of the park on the hills across the road. Running northeastsouthwest, Dorin Rd. sees two hills on its either sides at the project site. The eastern hill has been allocated to the first phase and the western one to the second phase of the park. The first phase of the park has already been opened to the public. It reaches $20 \mathrm{~m}$ above the road at the highest point. The west hill, however, projects $14 \mathrm{~m}$ above the road. Figures 6 and 7 demonstrate the longitudinal profile of the site.

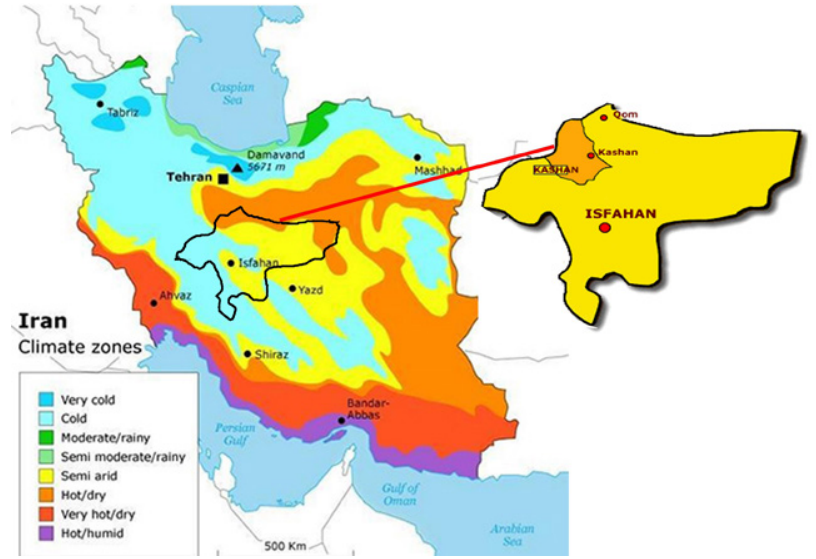

Figure 5. Kashan's location in Iran climate zones

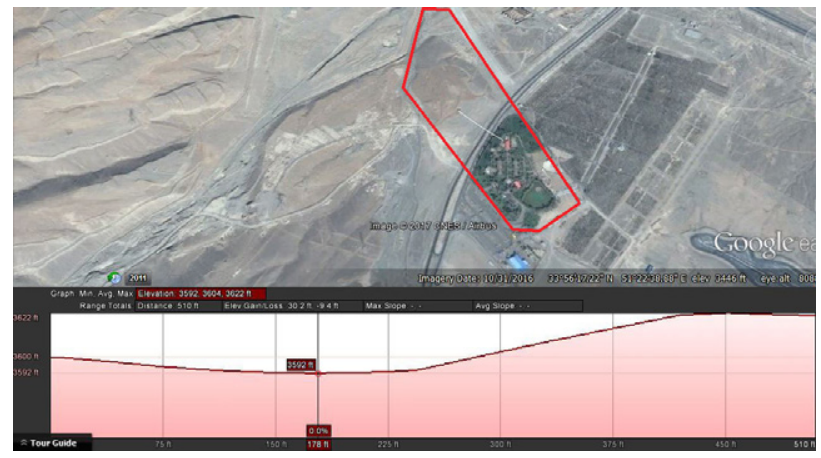

Figure 6. The longitudinal profile of the site extracted from Google Earth

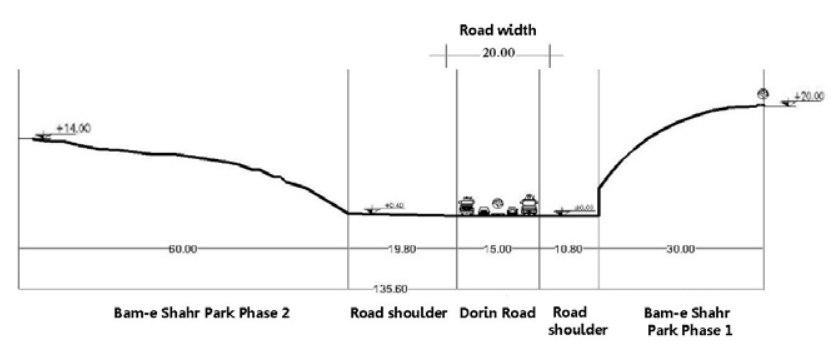

Figure 7. The longitudinal profile of the site

According to the profile provided, a 103-meter-long bridge is needed to connect the two parks on both sides of the road. To design a pedestrian bridge on this site, we face several issues:

1. The bridge must cover a span of 103 meters without a middle base. Because there is not enough space for the middle support column.

2. Designing a bridge with this span in a dry climate, where the cost of construction is high, is an issue for which a suitable solution must be considered.

3. Since it is a tourist site, the length of construction time should be minimized so that the use of the site would not be threatened. 


\subsection{Organizing design issues and goals}

In addition to the issues mentioned in the site analysis, in order to achieve other design needs, design criteria and user needs were also examined to explain reasonable design goals. Table 1 is the result of a simultaneous look at the criteria, user needs, and features of the design site that organizes the design goals.

Table 2 lists the general goals and demands in the design of the pedestrian bridge.

Table 2. General goals in the design of the pedestrian bridge (source: Author, 2018)

\begin{tabular}{|l|l|}
\hline \multicolumn{1}{|c|}{ Goals } & \multicolumn{1}{c|}{ Objectives } \\
\hline $\begin{array}{l}\text { Optimal } \\
\text { Structural } \\
\text { Design }\end{array}$ & $\begin{array}{l}\text { Reducing construction costs, avoiding the waste } \\
\text { of capital, materials }\end{array}$ \\
\hline Safety & $\begin{array}{l}\text { Unyielding structure, resistant to natural and } \\
\text { climatic factors, protection of pedestrians } \\
\text { against weather, safe access to the bridge from } \\
\text { entrances, adequate railing }\end{array}$ \\
\hline Strength & $\begin{array}{l}\text { Standard structural design, acceptable } \\
\text { deformation, and incorporation of suitable } \\
\text { materials }\end{array}$ \\
\hline Efficiency & $\begin{array}{l}\text { Effective and safe connection of the two } \\
\text { parks with the shortest path, long service life, } \\
\text { possibility to inspect and maintain different } \\
\text { parts of the structure, proper accessibility, } \\
\text { invitingness, compliant with the local } \\
\text { geographical, historical, and cultural context }\end{array}$ \\
\hline $\begin{array}{l}\text { Promoting } \\
\text { Tourism and } \\
\text { Providing a } \\
\text { Social Hub }\end{array}$ & $\begin{array}{l}\text { Visual attractiveness and charm, exhibition of } \\
\text { modern technology, exhibition of the rich local } \\
\text { architectural and cultural history, invitingness, } \\
\text { evocative of a sense of exploration over the } \\
\text { path, creation of memories along the path, } \\
\text { implementation of spaces for pause and vantage } \\
\text { points along the path }\end{array}$ \\
\hline $\begin{array}{l}\text { Climate } \\
\text { Compatibility }\end{array}$ & $\begin{array}{l}\text { Using accessible and adequate materials, } \\
\text { using forms with minimum surface exposed } \\
\text { to sunlight, protecting users against weather } \\
\text { conditions with a canopy }\end{array}$ \\
\hline
\end{tabular}

\section{Finding a bio-inspired solution}

\subsection{Natural models for bridge structures}

This section delves into natural design solutions for loadbearing structures with large spans. Figure 8 presents examples of natural structures, which can serve as sources of inspiration for bridge design.

Trees with nonlinear fractal geometry (Md Rian \& Sassone, 2014) are subjected to all types of loads from compression to tension, shear, and deflection, to which they exhibit excellent flexibility down to the leaves and twigs (Figure 6a). Three advantages of trees over human-made structures are their multi-functional nature, adaptive growth, and optimal hierarchy (Burgess \& Pasini, 2004). The branching system of trees has widely inspired load

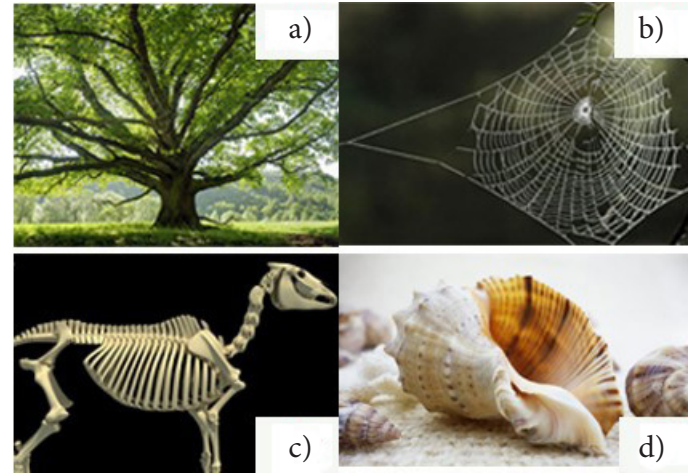

Figure 8. Biological structures used in bridge design: a) tree branches (Britannica, n.d.); b) spider web (Rimma, n.d.); c) quadruped spine (3dhorse, n.d.); d) seashells (Max pixel, n.d.)

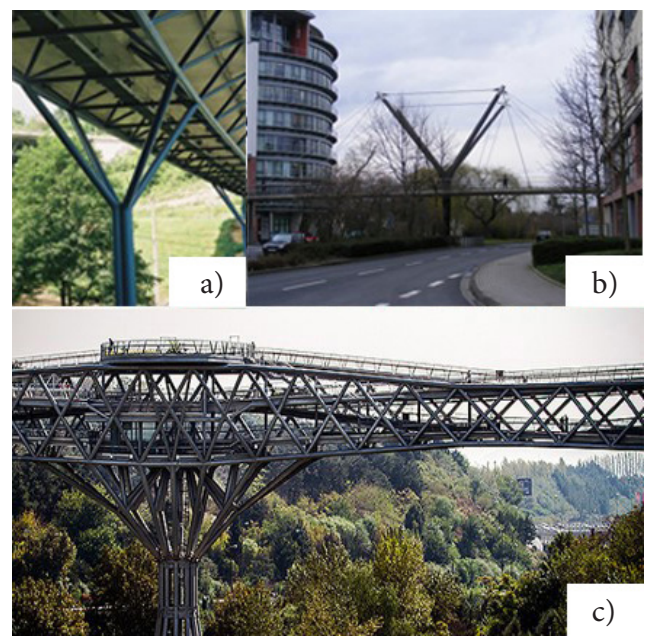

Figure 9. Germany bridge structural designs inspired by trees: a) Nsnback St. Bridge, Germany (Structurae, 2002); b) Hserning St. Bridge, Germany (Structurae.net); c) Tabiat Bridge, Iran (Guideiran, n.d.)

distribution in bridge support pillar design. Examples of such bridges can be seen in Figure 9.

The unique properties of spider silk are well-known. The stronger-than-steel fibers that put any artificial highstrength fiber to shame are also flexible and can take a wide range of different forms. The material has recently been shown to be not only strong, but also smart as it reacts to different types of stress (Mann, 2012). The spider web is a sophisticated example of architecture in the animal kingdom. Thanks to its viscoelasticity, the structure can absorb applied forces, distributing them across its branching network (Yeler, 2015). Scientists have attributed the stability of the spider web, even when it is partially damaged, to its nonlinear response to applied stresses (Martikka \& Pöllänen, 2012). The strength and flexibility of spider web have inspired tensile systems in several suspension structures. Suspension structures are known to be designed with the highest-rated materials for safety, which undermines their economic efficiency compared to similar, even heavier structures (Yin \& Yang, 2017). When 


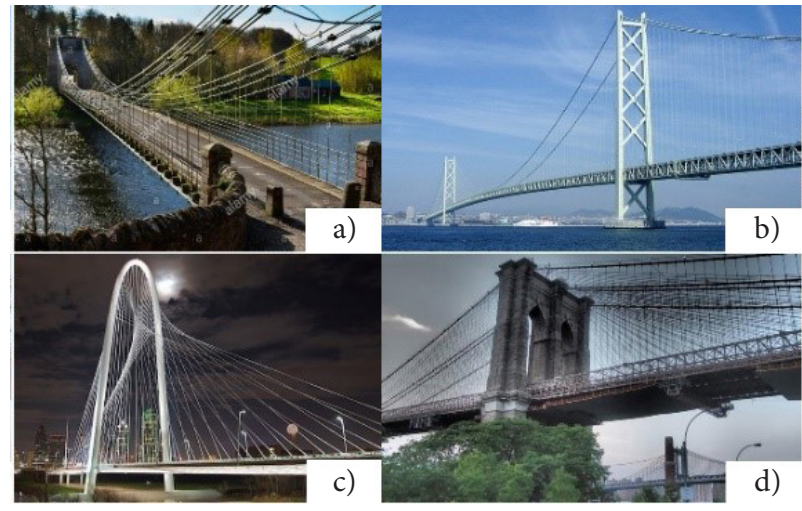

Figure 10. Spider-web-inspired, cable-stayed bridges: a) The Union Bridge, U.K. (Alamy, 2017); b) The Akashi Kaikyō Bridge, Japan (Domus, n.d.); c) The Margaret Hunt Hill Bridge, U.S. (Wikipedia, n.d.); d) The Brooklyn Bridge, U.S. (Snappygoat, n.d.)
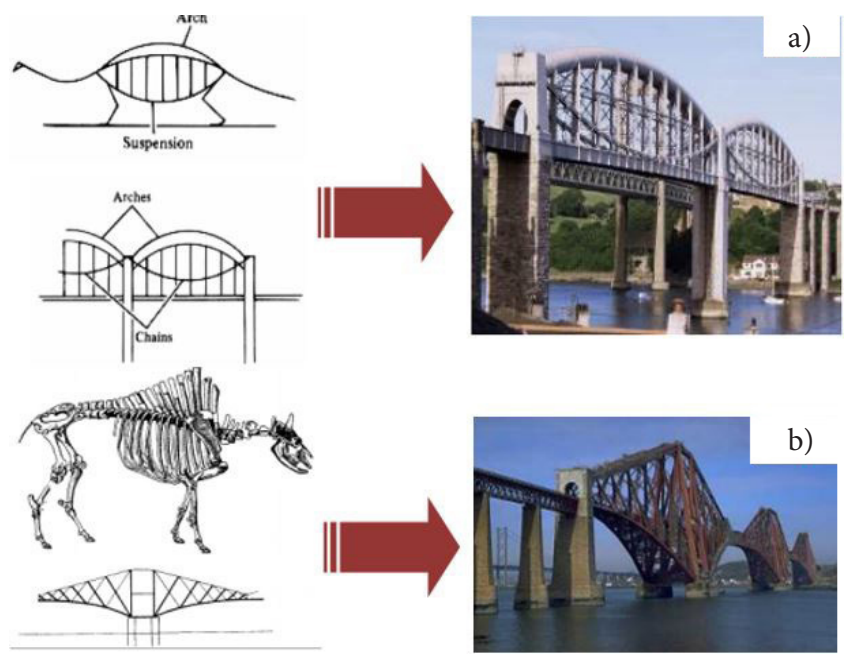

Figure 11. Bridges inspired by spine and skeleton: a) The Royal Albert Bridge, U.K. (Yeler, 2015); b) The Forth Bridge, U.K. (Yeler, 2015) he designed the Union Bridge, Samuel Brown, a pioneer in cable-stayed structures, was inspired by the spider web (Kawada, 2010). Figure 10 shows examples of cable-stayed bridges that emulate the spider web.

The vertebrae in human and animal bodies, composed of organic and inorganic parts, are some of the nature's most innovative creations; despite being hard and rigid, they can withstand large loads, allowing birds to fly and sea creatures to wander about in water, and shielding the creature's internal organs despite growth and development over the course of its life. In the nature, spine and rib cage work in harmony to secure the stability and survival of a species. The same concepts are also essential in human-made structures. Accordingly, the human spine and skeleton have long been a topic of interest for designers (Yeler, 2015).

The unique strength of the spine is the balanced function of the compressive and tensile elements together, which keeps the structure stable (Taghizadeh \& Bastanfard, 2012). Spine has evolved over the years to allow aquatic to terrestrial species (which are subject to different atmospheric and physical loads) to survive and move. Features such as strength, stability, and flexibility give the spine an unparalleled potential by which bionic technologies are inspired (Galbusera \& Bassani, 2019). In addition, research has shown that the axial skeleton of mammals is a highly modular structure (Randau \& Goswami, 2017).

This natural marvel has not been ignored by the designers since unique structures have been developed over the years inspired by human and animal spines. Figure 11 represent some examples of such bridges.

A plethora of shell-like structures could be found in the nature from seashells to turtle shells, the Crustacea, nutshells, plant leaves, and the skull. These natural shell structures aim to achieve strength at the minimum thickness and various, highly-efficient, three-dimensional forms with minimal use of material (Yelder, 2015).

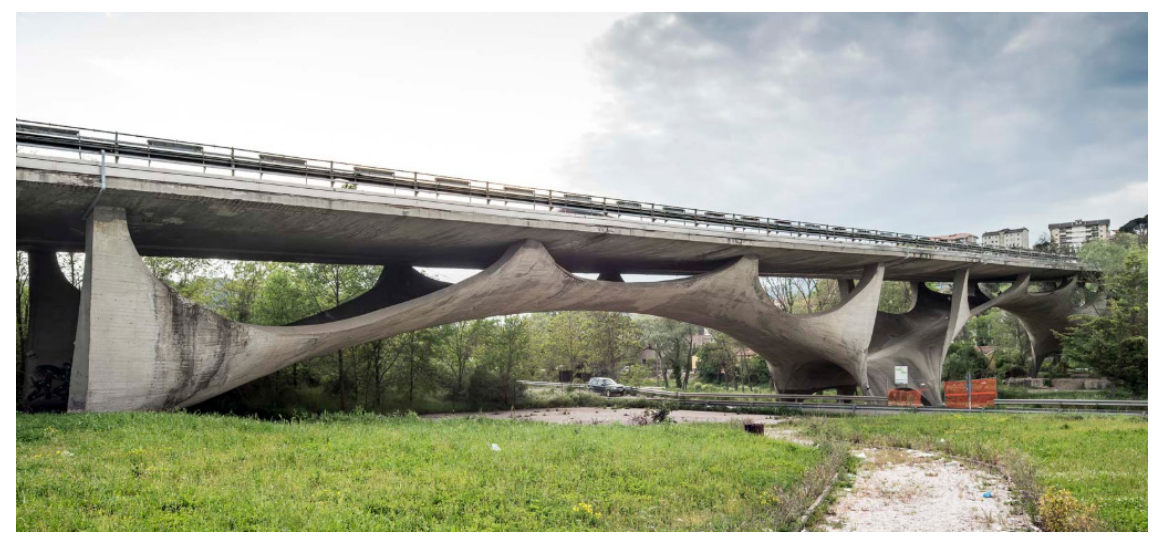

Figure 12. The Musmeci Bridge, Italy (Aloarchitettiroma, n.d.) 
Table 3. Comparison of biological patterns with design goals

\begin{tabular}{|c|c|c|}
\hline $\begin{array}{l}\text { Biological } \\
\text { pattern }\end{array}$ & Attributes & Fit to design goals \\
\hline Tree & $\begin{array}{l}\text { 1. Fractal and nonlinear geometry } \\
\text { 2. Being multifunctional } \\
\text { 3. Adjustable growth } \\
\text { 4. Optimal hierarchy } \\
\text { 5. Collecting loads in different directions and } \\
\text { transferring it vertically to the ground }\end{array}$ & $\begin{array}{l}\text { Since we do not need a middle pillar in the design of the } \\
\text { bridge, patterning from a tree is not suitable for our design }\end{array}$ \\
\hline $\begin{array}{l}\text { Spider } \\
\text { silk }\end{array}$ & $\begin{array}{l}\text { 1. Viscoelasticity } \\
\text { 2. Nonlinear reaction to stresses } \\
\text { 3. Strength } \\
\text { 4. Flexibility } \\
\text { 5. Lightness }\end{array}$ & $\begin{array}{l}\text { Spider web is suitable for bridge design owing to its flexibil- } \\
\text { ity, strength, and style, considering that suspension bridges } \\
\text { are also inspired by this pattern and have a successful back- } \\
\text { ground }\end{array}$ \\
\hline Spine & $\begin{array}{l}\text { 1. Composition of modular elements } \\
\text { 2. Possibility of horizontal and vertical design } \\
\text { 3. Cover large openings } \\
\text { 4. Strength } \\
\text { 5. Flexibility }\end{array}$ & $\begin{array}{l}\text { The backbone of four-legged animals, which covers a large } \\
\text { span without a middle pedestal and is capable of withstand- } \\
\text { ing significant loads, is suitable for bridge design. In addition, } \\
\text { its modular form can simplify the design process and allow } \\
\text { pre-fabrication }\end{array}$ \\
\hline Seashell & $\begin{array}{l}\text { 1. Strength } \\
\text { 2. Variety of forms } \\
\text { 3. Restrictions on the type of materials }\end{array}$ & $\begin{array}{l}\text { Variety of design forms is one of the advantages of this } \\
\text { biological pattern, which leads to aesthetic design. However, } \\
\text { the limitation of materials is one of its disadvantages }\end{array}$ \\
\hline
\end{tabular}

An example of shell structure is illustrated in Figure 12 , designed through the same approach.

A review of the advantages of each of the above biological models shows the spine to be the best one for a modular yet optimal structure, for it comprises smaller components with an integrated mechanism.

Table 3 compares the features provided by each of the above-mentioned biological patterns with design goals and issues to help us choose the best model.

\subsection{Selecting an appropriate biological pattern for the design}

How structural form relates to architecture leads to the superiority of one form over another to the extent that the optimal form is formed. In fact, the optimality of the form is achieved once there is integration in the form of architecture and structure and in this situation, the structure of the form, in addition to meeting the requirements of the structure, includes other aspects. These aspects include the adaptation of the form to the route of load transmission and the observance of economic funds, including the use of minimum materials and taking into account the cost and duration of its construction (Sabetghadam et al., 2018).

In a study conducted by Jiang et al. the method of prefabrication in construction is introduced as: an efficient solution to reduce costs (from machinery and materials to human resources), shortening construction time, prevention of schedule delays, specifically in severe weather, significant reduction in chaos on the design site, and so forth (Jiang et al., 2019).

Energy consumption is another critical factor in sustainable bridge construction and is calculated based on the weight of equipment, energy consumed per hour of operations, and the total construction time.
Rapid bridge construction is a novel approach that brings the concept of sustainable bridges closer to reality. This method entails a variety of techniques, processes, and technologies to reduce congestion due to construction while improving quality. Through this approach, all the constituents of a bridge could be pre-fabricated, which allows production under controlled conditions with the minimal impact on traffic and the environment (Korkmaz et al., 2012).

Furthermore, adopting a modular design and prefabrication are strategies toward sustainable architecture and economy in arid climates and enable substantial cost reductions (Akadiri et al., 2012).

Given the design issues introduced in Section 2.3, the pre-fabrication method can be a suitable solution to address an important part of the design issues. On the other hand, the requirement of this method of design and implementation is the use of modular forms. Therefore, among the proposed biological models, spine is the most appropriate model for our purposes since in addition to covering the span without a middle base, it has the property of being modular.

\subsection{Comparison of human spine and four-legged spine}

Spine in quadruped mammals is the primary protection for their spinal cords against impact and stress during movement. Moreover, the stiffness and stability of the spine provide support against body weight and forces created by muscle contraction for physiological and locomotive purposes (Galbusera \& Bassani, 2019).

Accordingly, quadruped spine was selected and studied as a convenient model for the Kashan footbridge. For a better understanding of the function of the quadruped 
spine and its differences with human spine, as a vertical structure, a comparison was made between horse and human spines.

The main tasks of the skeletal system in the body include:

- Improving stability and supporting the body.

- Protecting some parts of the body, such as the brain and internal organs.

- Facilitating movement using joints and muscles (Zolfaghari, 2015).

An anatomical comparison between the human body and that of a horse revealed certain similarities and differences in their function as vertical and horizontal load-bearing structures. The differences between the two structures could be discussed in three domains, namely components, anatomical planes, and curves.

The component differences were as follows:

1. Skull: horse skull is longer whereas human skull is oval-shaped and more rounded.

2. Neck (the cervical vertebrae): human and equine vertebral columns have the same number of vertebrae. Additionally, both have similar designs and functions and their differences are limited to size. The cervical vertebrae are longer and larger in horses (Zolfaghari, 2015).

3. Rib cage and ribs: the anatomical assembly is made up of thoracic vertebrae and their attached ribs. In horses, all ribs in the horse skeletal system attach to the sternum (the breast bone). The same is valid with all human ribs except for the two at the bottom-referred to as floating ribs. The horse rib cage is longer from the front to the back in comparison with the human rib cage, which is wider in the front. In the horse anatomy, the thoracic vertebrae feature long processes, which can reach up to $30 \mathrm{~cm}$ in length, provide a large leverage power (Same).

4. Lumbar vertebrae: no stabilizing structures, such as ribs or the pelvic bone, are found in this area to support the structure. The lumbar vertebrae are only supported by muscles (Same).

5. Sacral vertebrae and the pelvic bone: small triangular vertebrae are found under lumbar ones, which are known as sacral vertebrae. They are similar in both human and horse anatomies in terms of number and shape. In human skeletal system, the pelvis is positioned in a vertical plane whereas it is in front of and on a horizontal plane in horses. However, both have the same function (Same).

6. The coccyx or tailbone: The skeletal anatomies of humans and horses must also be compared. Three principal anatomical planes are considered for the body, which are named similarly, yet have different arrangements in humans and horses. The three planes are (Zolfaghari, 2015):

1. The sagittal plane: it divides, both human and horse bodies, into left and right parts. If the plane runs through the body, dividing it into two equal parts, it is called the median plane.
2. The frontal plane: it divides the human body into ventral and dorsal parts and the horse body to belly and back.

3. The horizontal plane: it divides the human body into superior and inferior parts and the horse body into caudal and cranial (Zolfaghari, 2015).

Figure 13 shows the anatomical planes in human and horse bodies.

The curves of equine and human spines can elucidate their functional differences. From the side view, three curves can be seen in the human vertebral column. These curves help the human spine with its vertical function by enhancing its resistance against vertical loads (Figure 14).

Axial curves are small in equine spine and different among horse breeds. The apparent curves of the horse spine are in fact created through the spinous processes and are not axial (Figure 15).
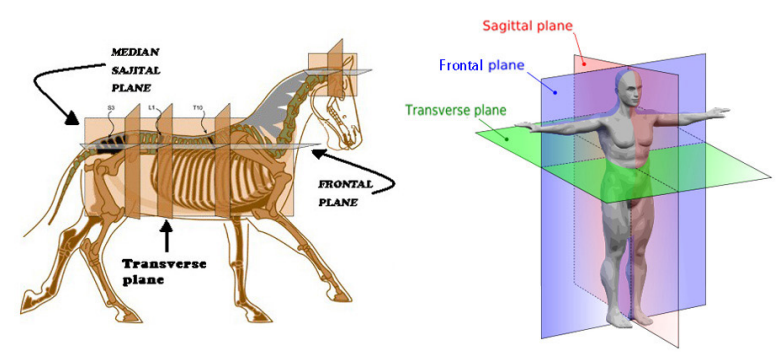

Figure 13. Equine and human body axial planes

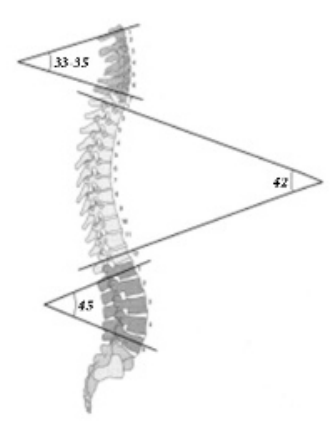

Figure 14. The side view and curves of human spine (Soma movement studio, n.d.)

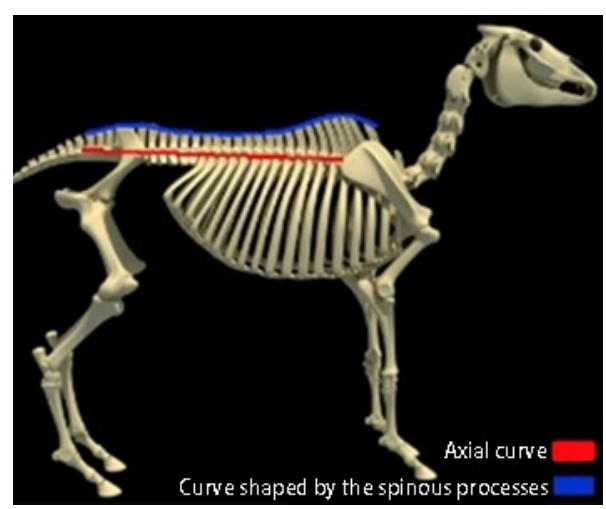

Figure 15 . The side view and curvature created by spinous processes (3dhorse, n.d.) 

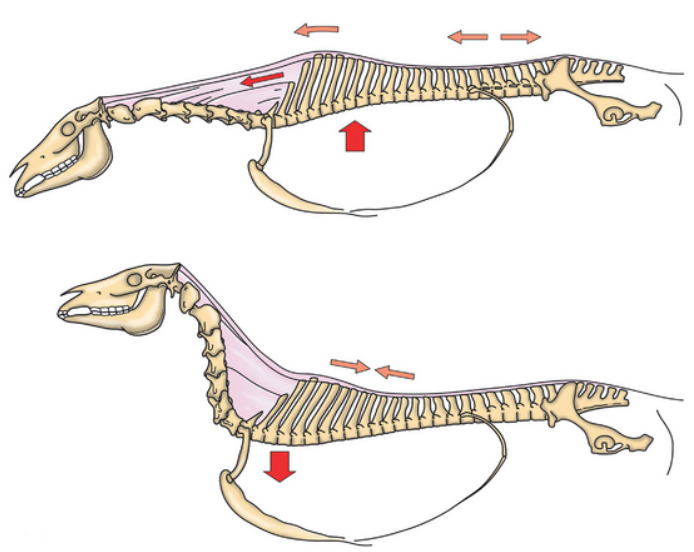

Figure 16. Axial curvature of spine with the creature's neck movement (Veteriankey, n.d.)

The processes act as a leverage and hold the creature's neck through ligaments, transferring the weight of the neck to the spine. The only stabilizing structures from the last thoracic vertebra to the last lumbar vertebra are muscles and ligaments. Processes create a positive curve in this area. The positive curve turns negative when the creature holds its head down, creating tension in the supraspinous ligament and compressing vertebrae (Weeren, 2016) (Figure 16).

\subsection{Proposed structural models of human and mammalian spine}

Human spine is best represented by a tensegrity model. Tensegrity models have no joints nor supports and the disks carry no load. In fact, the vertebrae are not connected directly and stay in place without touching. Each vertebra in the spine withstands loads similar to a tetrahedral structure. The sequence of tetrahedrons and their collective function, as a static but flexible pole, elucidates the spine function. The tetrahedral vertebrae are suspended from the pelvis by ligaments and muscles (Levin, 2002) (Figure 17).

The bow-and-string model is the latest attempt at representing mammal skeletal system. In this model, the bow represents the spine and the string indicates the linea alba, the rectus abdominis muscle, and other attachments. The model was initially introduced by Barthez in the 18th century; however, being ahead of its time, it was not widely accepted before 1946 when it was rediscovered by Slijper (Weeren, 2016).

The bow-and-string model is the only comprehensive representation of the entire mammal vertebral column (Figure 18).

In this model, the entire structure is intrinsically tensioned, similar to the archer's bow, thereby creating a dynamic balance, under which the changes in one component inevitably affect the biomechanical dynamics of others. Several elements are involved in the dynamic balance. Gravity is always exerted in the downward direction, straightening the bow. On the other hand, the contraction of abdominal muscles works to maintain the bow by bringing the two ends closer (Weeren, 2016).
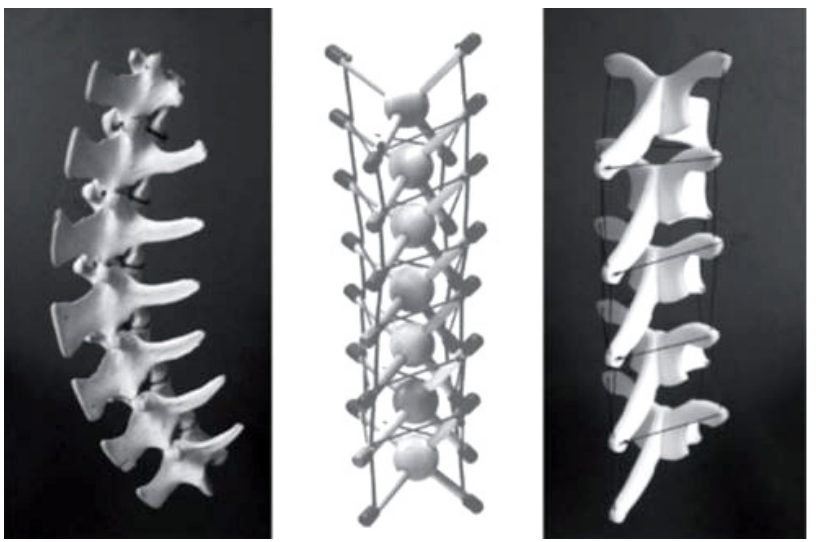

Figure 17. A tensegrity model showing the vertebra in place without touching (Journal of the royal society, n.d.)

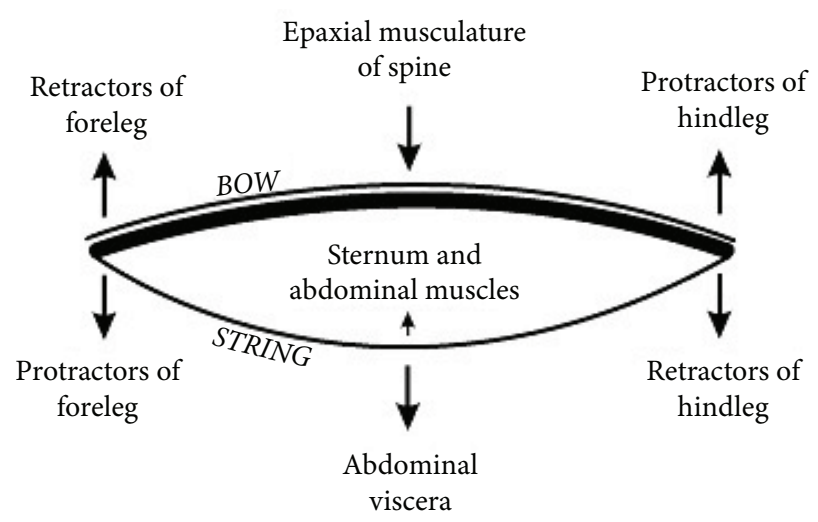

Figure 18. The bow-and-string model and the components representing the horse back movements (Veteriankey, n.d.)

\section{Design principles}

\subsection{Fundamental concept}

The first step in the conception of the design idea is to obtain the bridge components from the tetrahedral vertebra. As could be seen in Figures 19-21, the initial concept was developed and a scale model was created by an abstraction of the form of the vertebrae and the function of the spine as a tensegrity structure, in which vertebrae are suspended as compressive components in a tensile network.

The initial scale model revealed two remarkable issues with the concept. Primarily, the unchanging, monotonous, and motionless form of the structure undermine its attractiveness; secondly, the problematic structural function that was prone to large deformations. Human spine, as a vertical structure, is not the best source of inspiration for mechanics and load transfer in the horizontal structure of the bridge. Accordingly, equine spine was considered for it is considerably similar to the human vertebral column, yet at the same time, would help resolve the deformation problem, thanks to the small but key differences. 

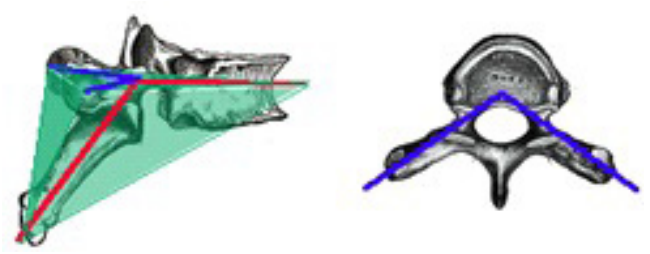

Figure 19. The tetrahedral structure of the vertebrae

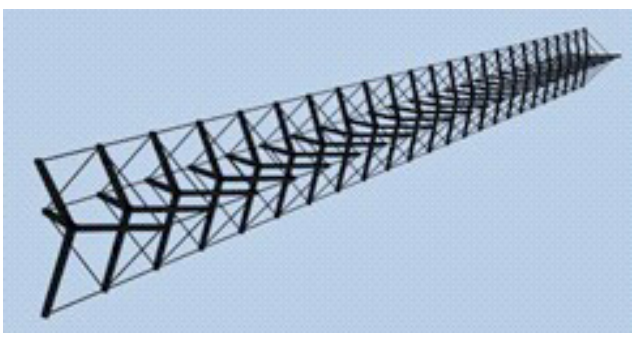

Figure 20. The three-dimensional initial concept

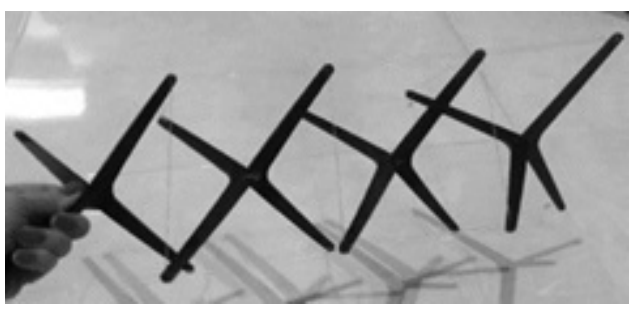

Figure 21. Conceptual scale model based on the tensegrity structure of spine

\subsection{Completing and correcting the concept}

As discussed earlier, when comparing the human and equine spines, the axial curve changes in the latter as the horse moves its head up and down, putting the supraspinous ligament under tension and creating a negative curve in the vertebral column by prestressing the vertebrae. In this configuration, the processes at the two ends of the equine spine are taller and acts as compressive leverages. In this case, a certain similarity exists between equine spine and cable-stayed bridges suspended on two pylons. The similarity is illustrated in Figure 22.

The initial concept was brought functionally closer to equine spine by adjusting the pylon heights in tetrahedral vertebrae, leading to a second concept different from a tensegrity structure and, more or less, functionally akin to a cable-held bridge. In the end, the structural form was modeled after the quadruped skeleton for load transfer using the Grasshopper plugin in Rhino; additionally, a scale model was created (Figure 23).

\subsection{Structural analysis}

In this section, the model was analyzed utilizing Karamba.

Figures 24 and 25 exhibit the graphical results of the analysis.

The analysis results were as follows:

- The stress peaked at the pylons on the two ends of the bridge whereas the maximum deformation was found in the middle.

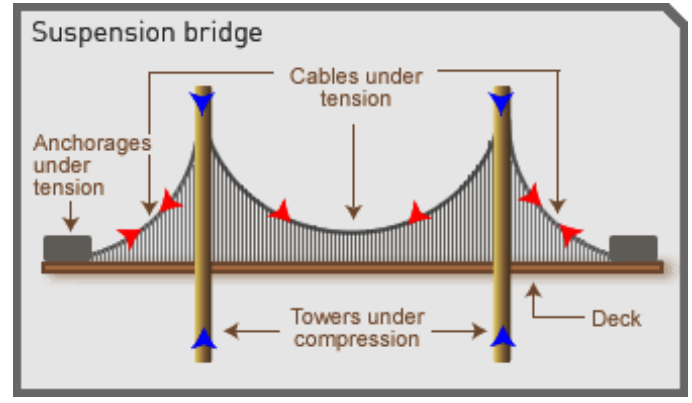

Figure 22. Similarities between load transfer in the equine spine and the suspension bridge with two pylons
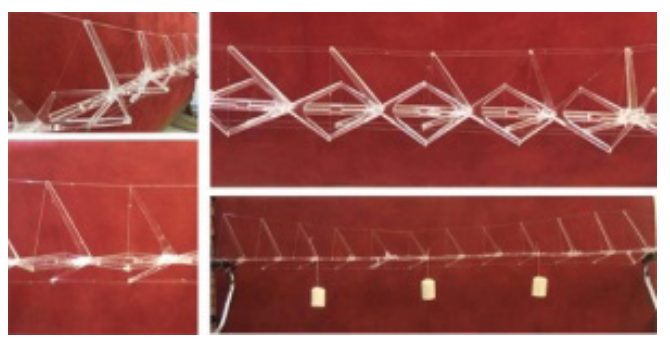

Figure 23. The longitudinal profile of the site extracted from Google Earth

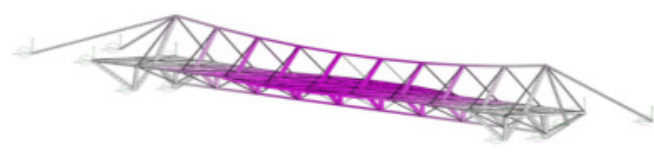

Figure 24. The graphical representation of the displacement of structural members

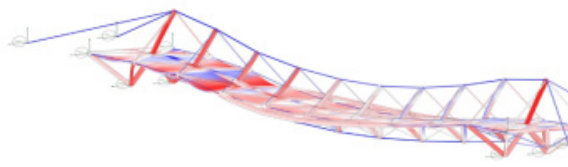

Figure 25. Exaggerated deformation under the specified load

- The asymmetry of the bridge plan resulted in different structural responses to loading on the two ends.

- Larger-than-expected dimensions were obtained in some elements.

- The weight of the structure was successfully reduced by $8 \%$ using prestressed cables.

Based on concept analysis results obtained from Karamba, corrections were made to the structure and the output was evaluated for stability via SAP2000 to obtain reliable sections.

These corrections included:

- Making the structure symmetrical to equalize structural responses to loading on both sides of the bridge.

- Putting a truss curve under the deck to adjust the load exerted on the pylons.

- Increasing the number of vertical elements from 10 to 14 , thereby making the middle spans smaller and adjusting the loads applied on the members.

- Adding slanted middle cables on both sides of the deck to adjust the load exerted on the pylons. 
Figure 26 illustrates the changes made to the bridge structure via SAP2000 in the layout plan.

Figure 27 depict the results of the final analysis. The analysis showed the loads in different structural elements. The largest loads are marked with red and the smallest ones with grey.

Evidently, given the above figures, none of the structural members were under critical conditions and the software managed to find the best design option from the list of sections.

Figure 28 shows the typology of the prefabricated structural members that will be installed through bolt connections.

Figure 29 illustrates the connection of the main structural components.
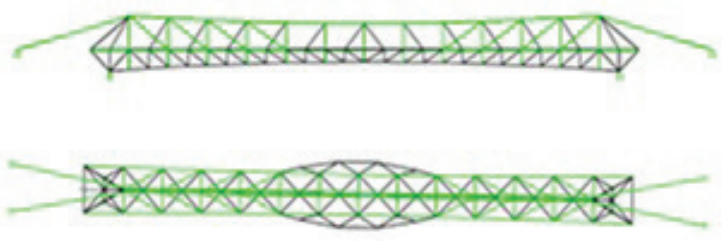

Figure 26. The corrected layout plan of the structure

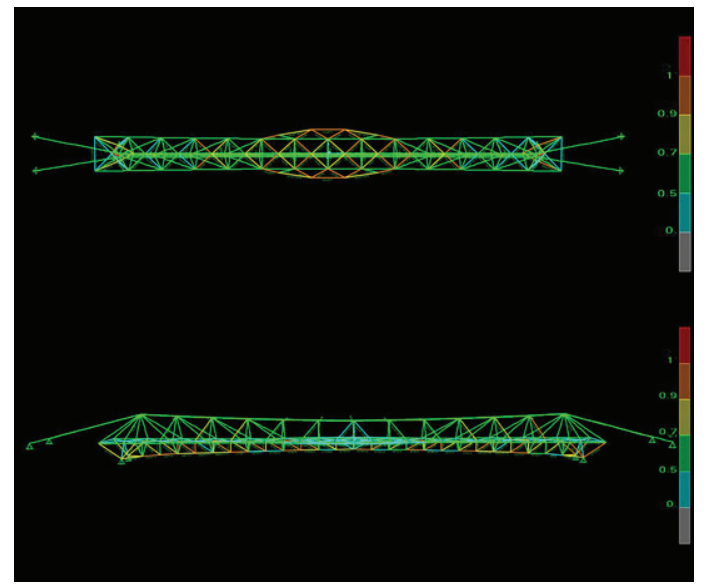

Figure 27. The graphical representation of the loads in the structural members

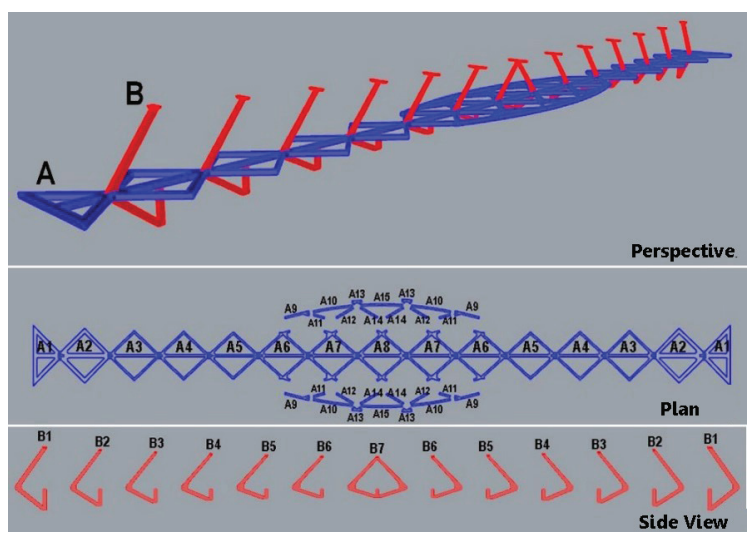

Figure 28. Typology of the structural components
In the final bridge design, shade sails were employed for canopy. Figure 30 depicts the final bridge without a canopy.

Multiple views of the final design are presented in Figure 31.

Plan and section of the final design are presented in Figure 32.

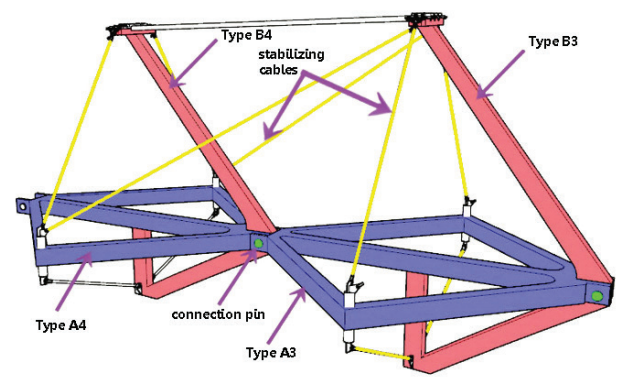

Figure 29. Connections between the two groups of main components and pins and stabilizing cables

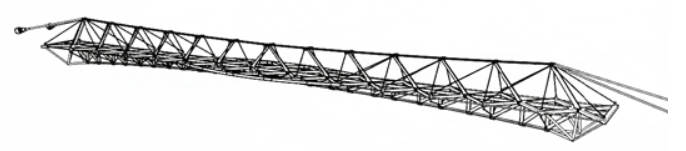

Figure 30. The final 3D rendition of the bridge without shades

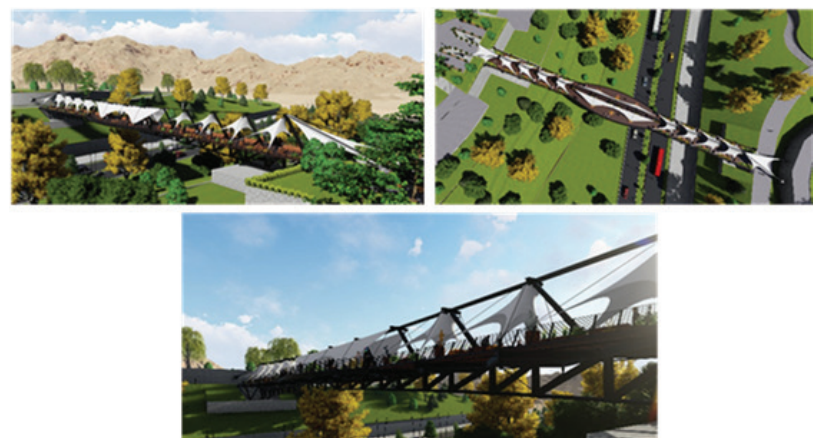

Figure 31. The final design

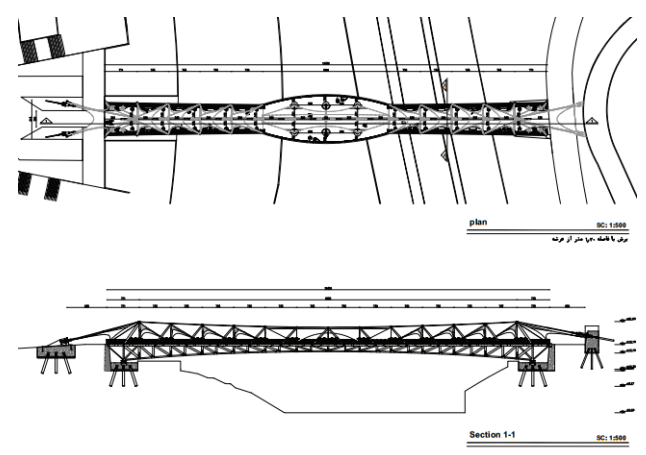

Figure 32. The final plan and section 


\section{Conclusions}

The evolution and promotion of natural and biological structures of living organisms has been done during thousands of years of formation and using and evaluating certain principals governing them, an optimal design can be achieved. In this research, the possibility of using bionic ideas in the design of the steel structure of a pedestrian bridge with the aim of achieving the appropriate form of the structure was investigated. The study on the body structure of animals showed that their spine is optimal in terms of structure and form to withstand the loads. Moreover, if this structure is utilized in design of human-made structures, the optimal design could be achieved. Due to the similarity of the structure and the way of transferring the load of the bridge deck to the supports, with the structure of transferring the load of the animals on their legs, the use of their vertebral column form pattern in the design of the bridge structure was simulated. To this end, the structure and form of the vertebral column of horse skeleton was used to design the elements and the general form of the structure of the bridge. In the critical area of the bridge structure, significant bending and shear stresses were created, the solution of which was obtained by comparing the bridge with the skeletal structure of horse. A combination of truss and tensegrity structure was employed to design the overall shape of the bridge structure. The initial idea was analyzed both as a scale model and using caramba and its functionality and stability were evaluated. Subsequently, the stability of the bridge skeleton set and the accuracy of the designed form in terms of placement in the stress range and permissible deformations were re-evaluated with Sap 2000 finite-element software. The results revealed that modeling the shape of an animal's spine in bridge design controls stress and deformation and ultimately, provides the optimal form in the design. In general, it could be stated that in biological structures, such as the backbone of animals, load transfer through net pressure and tension, despite slight bending, is done optimally; by modeling them in the skeleton design of similar structures, a more appropriate form would be achieved.

\section{References}

3dhorse. (n.d.). Horse skeleton 3D model. https://www.3dhorse. com/collections/3d-animals

Akadiri, P. O., Chinyio, E. A., \& Olomolaiye, P. O. (2012). Design of a sustainable building: a conceptual framework for implementing sustainability in the building sector. Buildings, 2(2), 126-152. https://doi.org/10.3390/buildings2020126

Alamy. (2017, April 10). The Union Chain Bridge, crossing the River Tweed near Horncliffe, completed in 1820 by Capt Samuel Brown RN. https://www.alamy.com/

Ali El-Zeiny, R. M. (2012). Biomimicry as a problem solving methodology in interior architecture. Procedia - Social and Behavioral Sciences, 50, 502-512.

https://doi.org/10.1016/j.sbspro.2012.08.054

Al-Sehail, O. (2017). A biomimetic structural form: developing a paradigm to attain vital sustainability in tall architecture. International Journal of Civil, Environmental, Structural, Construction and Architectural Engineering, 11(3), 322-332.
Aloarchitettiroma. (n.d.). Ponte Musmeci, un'opera d'arte dei nostri giorni: $i$ vincitori del progetto di restauro. http://www.aloarchitettiroma.it/ponte-musmeci-unopera-darte-dei-nostrigiorni-i-vincitori-del-progetto-di-restauro/

Aziz, M. S., \& El Sherif, A. Y. (2016). Biomimicry as an approach for bio-inspired structure with the aid of computation. Alexandria Engineering Journal, 55(1), 707-714.

https://doi.org/10.1016/j.aej.2015.10.015

Britannica. (n.d.). Saving the world's largest trees. https:// www.britannica.com/story/saving-the-worlds-largest-trees

Burgess, S. C., \& Pasini, D. (2004). Analysis of the structural efficiency of trees. Journal of Engineering Design, 15(2), 177-193.

Domus. (n.d.). There's not a single longest bridge in the world. https://www.domusweb.it/en/architecture/2020/04/08/theresnot-a-single-longest-bridge-in-the-world.html

Galbusera, F., \& Bassani, T. (2019). The spine: a strong, stable, and flexible structure with biomimetics potential. Biomimetics, 4(3), 60. https://doi.org/10.3390/biomimetics4030060

Guideiran. (n.d.). Tabiat Bridge. http://guideiran.com/portfolio/ tabiat-bridge/

Hu, N., Feng, P., \& Dai, G. L. (2013). The gift from nature: bioinspired strategy for developing innovative bridges. Journal of Bionic Engineering, 10(4), 405-414.

https://doi.org/10.1016/S1672-6529(13)60246-2

Yeler, M. G. (2015). Influences of the living world on architectural structures: an analytical insight. Uludağ University Journal of The Faculty of Engineering, 20(1), 23-38. https://doi.org/10.17482/uujfe.14962

Yin, J., \& Yang, W. (2017). Review of the research on "structural bionic" method of large sculpture. IOP Conference Series: Materials Science Enginering, 242, 012083.

https://doi.org/10.1088/1757-899X/242/1/012083

Jiang, Y., Zhao, D., Wang, D., \& Xing, Y. (2019). Sustainable performance of buildings through modular prefabrication in the construction phase: a comparative study. Sustainability, 11(20), 5658. https://doi.org/10.3390/su11205658

Journal of the royal society. (n.d.). Design and control of compliant tensegrity robots through simulation and hardware validation. https://royalsocietypublishing.org/doi/full/10.1098/ rsif.2014.0520

Kawada, T. (2010). History of the modern suspension bridge: solving the dilemma between economy and stiffness. ASCE Press. https://doi.org/10.1061/9780784410189

Korkmaz, K. A., Syal, M., Harichandran, R. S., \& Korkmaz, S. (2012). Implementation of sustainability in bridge design, construction and maintenance. Michigan Department of Transportation. http://www.michigan.gov/documents/mdot/RC1586_413209_7.pdf

Levin, S. M. (2002). The tensegrity-truss as a model for spine mechanics: biotensegrity. The Journal of Mechanics in Medicine and Biology, 2(3\&4), 375-388.

https://doi.org/10.1142/S0219519402000472

Mann, A. (2012). Spider silk is strong because it's smart. https:// www.wired.com/2012/02/spider-web-strength/

Martikka, H., \& Pöllänen, I.(2012). Design of innovative web structures based on spider web optimality analysis. Mechanical Engineering Research, 2(1), 44-63.

https://doi.org/10.5539/mer.v2n1p44

Max pixel. (n.d.). Nature beautiful sea beauty Seashell Shell Shells. https://www.maxpixels.net/Shells-Sea-Beauty-NatureSeashell-Beautiful-Shell-1348742

Md Rian, I., \& Sassone, M. (2014). Tree-inspired dendriforms and fractal-like branching structures in architecture: A brief historical overview. Frontiers of Architectural Research, 3(3), 298-323. https://doi.org/10.1016/j.foar.2014.03.006 
Mosseri, A. (2004). Structural design in nature and in architecture. In M. W. Collins, \& C. A. Brebbia (Eds.), Design and nature II (pp. 589-599). WIT Press.

Qaruni Esfahani, F. (2015). Design in nature: bionic architecture. Tehran (in Farsi).

Randau, M., \& Goswami, A. (2017). Morphological modularity in the vertebral column of Felidae (Mammalia, Carnivora). BMC Evolutionary Biology, 17, 133. https://doi.org/10.1186/s12862-017-0975-2

Rimma. (n.d.). Laba-laba ternyata punya manfaat yang baik untuk rumahmu, kamu sudah tahu? https://www.rimma. co/66315/inspiration/home/laba-laba-ternyata-punya-manfaat-yang-baik-untuk-rumahmu-kamu-sudah-tahu/

Sabetghadam, Z., Alami, B., Sadeghpour, A., \& Pachenari, A. (2018). Form optimization of truss columns with inspiration from the helix bone structure. Journal of Iranian Architecture \& Urbanism, 9(16), 157-168 (in Farsi).

Sadeghpour, A., Divandari, J., \& Golkar, N. (2017). A bionic approach to footbridge design [Conference presentation]. 11th International Assembly of Civil Engineering, Tehran, University of Tehran (in Farsi).

Sarikaya, M. (1994). An introduction to biomimetics: a structural viewpoint. Microscopy Research and Technique, 27, 360375. https://doi.org/10.1002/jemt.1070270503

Snappygoat. (n.d.). Brooklyn Bridge. https://snappygoat.com/ free-public-domain-images-brooklyn_bridge_bridge_new/
Soma movement studio. (n.d.). Nerdilates (pilates for nerds). http://www.aloarchitettiroma.it/ponte-musmeci-unoperadarte-dei-nostri-giorni-i-vincitori-del-progetto-di-restauro/

Structurae. (2002, June 9). Nesenbach Valley Bridge. https://structurae.net/en/media/2261-nesenbach-valley-bridge

Structurae. (2008, April 14). Dragon Bridge. https://structurae. net/en/structures/dragon-bridge

Structurae. (n.d.). Campo Volantin footbridge. https://structurae. net/en/structures/campo-volantin-footbridge

Taghizadeh, K., \& Bastanfard, M. (2012). The anatomy of a human body, a model to design smart high building. Science and Technology, 2(1), 8-14. https://doi.org/10.5923/j.scit.20120201.02

Technolite. (n.d.). Architectural. https://meinhardtgroup.com/ offices/singapore/

Veteriankey. (n.d.). The neck and back. https://veteriankey.com/ the-neck-and-back/

Vincent, J. F. V. (2001). Stealing ideas from nature. In S. Pellegrino (Ed.), Deployable structures (pp. 51-58). Springer. https://doi.org/10.1007/978-3-7091-2584-7_3

Weeren, R. V. (2016). Kinematic of the equine back and pelvis. https://veteriankey.com/kinematics-of-the-equine-back-andpelvis/

Wikipedia. (n.d.). Margaret Hunt Hill Bridge. https://en.wikipedia.org/wiki/Margaret_Hunt_Hill_Bridge

Zolfaghari, N. (2015). A comparison of human and equine anatomies (in Farsi). http://www.paddock.ir/knowledge. asp?pid=2\&tid=972\&title $=$ 